\title{
GUATEMALA 2007: UN AÑO DE CONTRASTES PARA
}

\section{LA DEMOCRACIA}

\author{
Guatemala 2007: A Year of Contrasts for Democracy
}

\author{
DINORAH AZPURU \\ Wichita State University \\ LIGIA BLANCO \\ Universidad Rafael Landívar
}

\begin{abstract}
RESUMEN
El año 2007 fue un año de contrastes para la democracia guatemalteca, en el cual se dieron aspectos positivos, pero también se evidenciaron serios problemas. El proceso político en 2007 giró en torno a las Elecciones Generales realizadas en el segundo semestre del año. En los meses previos a las elecciones pareció incrementarse la violencia, la cual llegó incluso a afectar a miembros de varios partidos políticos. Los altos niveles de inseguridad prevalecientes hicieron que dicho tema se convirtiera en uno de los principales ejes de la campaña electoral, en la cual por otro lado abundó el negativismo y los ataques verbales entre los contendientes. Sin embargo, tanto la primera como la segunda vuelta electoral se desarrollaron en un ambiente de tranquilidad y los resultados fueron reconocidos prontamente por los partidos políticos participantes y avalados por observadores nacionales e internacionales. $\mathrm{La}$ distribución geográfica del voto fue otro elemento clave en estas elecciones, ya que el candidato ganador, Álvaro Colom, resultó siendo el primer presidente electo sin haber triunfado en la capital del país.
\end{abstract}

Palabras clave: Elecciones, partidos políticos, violencia, democracia, nuevas autoridades.

\begin{abstract}
2007 was a year of contrasts for Guatemalan democracy; there were positive aspects but also serious problems. The political process in 2007 pivoted around the general elections that took place in the last quarter of the year. In the months preceding the elections violence seemed to increase, striking even members of several political parties. The high levels of insecurity in the country made this issue one of the main topics of the electoral campaign, which was characterized by negative verbal attacks between the contenders. However, both the first-round and the run-off elections were conducted peacefully and the results were promptly recognized by the parties participating in the event and validated by local and international observers. The geographic distribution of the vote was a key element in these elections given that the winning candidate, Álvaro Colom, is the first president elected without having won the capital.
\end{abstract}

Key words: Elections, political parties, violence, democracy, new authorities. 


\section{TEMAS SALIENTES EN LA REALIDAD NACIONAL Y SU IMPACTO POLÍTICO}

\section{Coyuntura social}

El país fue marcado a lo largo del año 2007 por altos niveles de violencia criminal que rebasaron la capacidad de acción de las fuerzas de seguridad pública. Se estima que diariamente son cometidos alrededor de 17 homicidios, especialmente en el área urbana, la cual presenta niveles de violencia mucho mayores que las áreas rurales, en las cuales habita la mayor parte de población indígena. La violencia y la delincuencia han sido identificadas por la mayoría de guatemaltecos como los principales problemas del país y algunos estudios han mostrado que la confianza en las instituciones democráticas se ve minada por la percepción y la victimización de violencia y criminalidad existentes. ${ }^{1} \mathrm{Se}$ ahonda en este tema porque dada la magnitud del mismo, el combate a la inseguridad se convirtió en uno de los temas centrales de la campaña electoral de 2007. La violencia alcanzó incluso a miembros de varios partidos políticos participantes en el proceso electoral, habiéndose contabilizado 57 asesinatos políticos durante el mismo. Esto contrastó con los anteriores procesos electorales realizados desde la apertura democrática en Guatemala en el año 1985 durante los cuales los asesinatos de índole política habían casi desaparecido.

De acuerdo a un informe del Programa de Naciones Unidas para el Desarrollo (PNUD) hecho público a finales de 2007, Guatemala es uno de los países más violentos e inseguros en Latinoamérica. ${ }^{2}$ En la Tabla 1 se observan algunos datos relacionados con la victimización y la percepción de la violencia en diversos países de la región latinoamericana, en la cual se evidencia que Guatemala está entre los países más violentos y que el problema se manifiesta con especial fuerza en las áreas urbanas.

Tabla 1: La violencia en Guatemala en perspectiva comparada

\begin{tabular}{lcc}
\hline País & $\begin{array}{c}\text { Homicidios por 100.000 } \\
\text { habitantes (2005) }\end{array}$ & $\begin{array}{c}\text { Porcentaje que opinó que } \\
\text { la violencia es el principal } \\
\text { problema del país en 2006 (2) }\end{array}$ \\
\hline El Salvador & $(1)$ & 44,8 \\
Honduras & 59,91 & 35,4 \\
Guatemala (nacional) & 59,6 & 49,5 \\
-Ciudad de Guatemala & 44,24 & 62,3 \\
-Municipios no indígenas & 108 & $\mathrm{n} / \mathrm{d}$ \\
-Municipios indígenas & 58,21 & $\mathrm{n} / \mathrm{d}$ \\
-Ubicación urbana & 15,78 & 55,3 \\
-Ubicación rural & $\mathrm{n} / \mathrm{d}$ & 44,3 \\
\hline
\end{tabular}

Ver Azpuru, Dinorah. Cultura política de la democracia en Guatemala.

Ver PNUD Guatemala. Informe estadístico de la violencia en Guatemala. 


\begin{tabular}{lcc}
\hline País & $\begin{array}{c}\text { Homicidios por 100.000 } \\
\text { habitantes (2005) }\end{array}$ & $\begin{array}{c}\text { Porcentaje que opinó que } \\
\text { la violencia es el principal } \\
\text { problema del país en 2006 (2) }\end{array}$ \\
\hline Colombia & $(1)$ & 53,2 \\
Venezuela & 43,01 & 57,9 \\
República Dominicana & 41,22 & 48,0 \\
Brasil & 28,7 & 30,8 \\
Ecuador & 23,97 & 5,1 \\
Paraguay & 16,77 & 13,4 \\
Nicaragua & 16,14 & 4,9 \\
Costa Rica & 14,38 & 21,3 \\
Argentina & 7,46 & $\mathrm{n} / \mathrm{d}$ \\
Uruguay & 5,71 & 15,4 \\
Chile & 5,63 & 41,2 \\
México & 1,98 & 30,8 \\
Panamá & $\mathrm{n} / \mathrm{d}$ & 21,3 \\
Bolivia & $\mathrm{n} / \mathrm{d}$ & 4,5 \\
Perú & $\mathrm{n} / \mathrm{d}$ & 10,3 \\
\hline
\end{tabular}

$\mathrm{n} / \mathrm{d}$ : No disponible.

(1) Fuente: Informe Estadístico de la Violencia en Guatemala, PNUD (2007).

(2) Fuente: Base de datos de la encuesta Barómetro de las Américas, Vanderbilt University. Aquí se muestra la sumatoria de las menciones a la delincuencia, crimen, violencia, narcotráfico, pandillas, terrorismo y secuestro.

Las causas de los altos niveles de violencia y criminalidad en Guatemala son diversas y complejas, y la discusión de las mismas va más allá del alcance de este artículo. No obstante, es importante señalar que la debilidad institucional para combatir dichos problemas ha sido repetidamente mencionada como una de las causas. Los efectivos de la Policía Nacional Civil son insuficientes para generar un ambiente de seguridad. Por otro lado, el sistema penitenciario no cuenta con las suficientes instalaciones para la cantidad de reclusos, tanto que las cárceles sobrepasan en un $20 \%$ su capacidad máxima. La debilidad del Estado y la ineficiencia del gobierno han impedido desarrollar políticas públicas de seguridad que no solamente den soluciones inmediatas al problema, sino que además lo ataquen de raíz. ${ }^{3}$ Adicionalmente, el sistema de justicia ha sido altamente deficiente y la mayoría de los crímenes no llegan a ser resueltos por el mismo. Aunado a lo anterior, la crisis generada por el asesinato en marzo de 2007 en territorio guatemalteco de tres diputados salvadoreños al Parlamento Centroamericano, así como la posterior ejecución de cuatro policías sindicados por las autoridades guatemaltecas de ser los autores materiales del crimen, evidenció la estructura con que cuenta el crimen organizado, y que se ha insertado en el aparato de gobierno (ver Anuario 2006). En este contexto, en el año 2007 se logró la aprobación del 
Congreso para la creación de la denominada Comisión Internacional contra la Impunidad en Guatemala (CICIG), la cual será presidida por las Naciones Unidas.

Los altos niveles de desigualdad y pobreza que persisten en el país también han sido mencionados como posibles causas de la violencia existente. En el año 2007 el Índice de Desarrollo Humano para Guatemala (IDH) mejoró ligeramente con relación al año anterior pero no logró mejorar el ranking del país a nivel continental; Guatemala nuevamente ocupó el penúltimo lugar de los países del continente americano sólo seguido por Haití. La Encuesta Nacional sobre Condiciones de Vida (ENCOVI) 2006 señala que el 52\% de la población se encuentra en situación de pobreza, y de este total un 15,2\% de los ciudadanos es considerado como extremadamente pobre. ${ }^{5}$

En otro orden de ideas, en el país se realizaron a lo largo del año una serie de consultas populares informales en varios departamentos del país sobre la explotación minera, la cual ha ido en aumento en años recientes. ${ }^{6}$ Finalmente, el ámbito de la educación pública continuó siendo conflictivo (ver Anuario 2006). En el mes de mayo, los maestros integrados a la Asociación Nacional del Magisterio (ANAM) suspendieron labores durante 21 días para presionar al gobierno, entre otras cosas, a concluir un Pacto Colectivo, aprobar un aumento del 15\% y dar marcha atrás en algunas políticas educativas, tales como la supresión del llamado PRONADE (Programa Nacional de Educación). ${ }^{7}$ Dichas acciones del magisterio generaron críticas de diversos sectores.

\section{Coyuntura económica}

La política económica de Guatemala durante el gobierno saliente de Óscar Berger se centró en la suscripción de acuerdos comerciales para mejorar el acceso de los productos guatemaltecos a mercados internacionales, atraer inversiones y generar más empleos. El mayor logro en este aspecto fue la ratificación del Tratado de Libre Comercio con Estados Unidos, Centroamérica y República Dominicana (TLC-CARD) en 2006. ${ }^{8}$ Durante 2007

4 El Índice de Desarrollo Humano para Guatemala según el Informe de Desarrollo Humano 2007 fue 0.689, ligeramente superior al índice de 0.673 obtenido en el Informe de 2006. Esto colocó al país en la posición 118 del ranking mundial. El IDH para Guatemala ha venido mejorando consistentemente desde la apertura democrática en 1985, pero no en forma suficiente. Ver Prensa Libre "Un doloroso penúltimo lugar."

5 Instituto Nacional de Estadística. Cómo estamos viviendo, Encuesta Nacional sobre Condiciones de Vida.

6 Las consultas son promovidas por diferentes organizaciones no gubernamentales enfocadas en el desarrollo sostenible, que argumentan que la población y el país en general no han recibido ningún beneficio y que pueden haber efectos negativos en el medio ambiente y en la salud de la población; sin embargo el gobierno continuó rechazando tales consultas populares, insistiendo en que son mecanismos de decisión no vinculantes. Solamente el Tribunal Supremo Electoral puede convocar a consultas directas con efectos vinculantes.

$7 \quad$ PRONADE es un programa paralelo de contratación de maestros creado en 1994, los cuales son supervisados por los padres de familia en comunidades aisladas del país, y no por los supervisores del Ministerio de Educación. Evaluaciones técnicas han mostrado la efectividad del programa, pero los líderes magisteriales señalan que los maestros contratados en el marco de ese programa carecen de protección laboral.

8 Si bien se esperaba que en este año se pudieran empezar a percibir beneficios de la firma del TLC con EE.UU., se estima que su impacto no ha sido significativo hasta el momento. Según datos recabados por la Asociación de Investigación y Estudios Sociales (ASIES), el 62\% de los exportadores dijeron que sus ventas no habían variado desde la entrada en vigor del Tratado, mientras que $19 \%$ afirmaron que sus exportaciones habían disminuido y otro 19\% dijo que sus exportaciones se incrementaron. Ver ASIES, “Evaluación Económica: Primer Semestre 2007". 
se continuó negociando tratados de libre comercio con Brasil, Panamá, Chile, Colombia, Canadá, Belice y la Unión Europea. Actualmente el país ocupa el lugar 74 en cuanto a apertura comercial se refiere alrededor del mundo. ${ }^{9}$

Si bien esta apertura ha venido generando crecimiento económico, a diez años de la firma de los Acuerdos de Paz no ha disminuido la desigualdad en la distribución de la riqueza. Según un informe de la Comisión Económica para América Latina y el Caribe (CEPAL) el Producto Interno Bruto (PIB) creció en un 5,6 por ciento en $2007 .{ }^{10}$ En contraste, según datos de la Superintendencia de Bancos y el Programa de las Naciones Unidas para el Desarrollo (PNUD), la situación para la mayoría de trabajadores no ha variado y sus ingresos no han crecido en la misma relación que la economía macro. Según estimaciones del Instituto Nacional de Estadística (INE) la Población Económicamente Activa (PEA) es de cinco millones de personas, pero sólo un millón tiene empleo formal y está afiliado al Seguro Social. El resto trabaja en el sector informal y cerca del $12 \%$ está desempleado. ${ }^{11}$ La desigual distribución de los beneficios del libre comercio ha generado protestas de algunos sectores sociales organizados, pero únicamente los partidos políticos de izquierda más radical se manifestaron en contra de dichos acuerdos. La mayoría de candidatos en la campaña del 2007 se abstuvo de mencionar el tema.

En el área comercial se ha visto un crecimiento en las exportaciones pero Guatemala continúa teniendo un déficit comercial importante, sintomático de procesos largos como la globalización y la apertura de mercados, un aparato productivo pequeño y poco competitivo, sumado a una moneda sobrevaluada que abarata las importaciones y desincentiva las exportaciones. De no ser por las remesas -que subsidian el consumo- y las inversiones, así como los préstamos del exterior, Guatemala tendría dificultades para mantener la estabilidad macroeconómica. El total de remesas enviadas cada año representa el 11\% del Producto Interno Bruto (PIB). ${ }^{12}$ Es por ello que las deportaciones de guatemaltecos indocumentados de Estados Unidos tienen un impacto enorme en la economía nacional. ${ }^{13}$ Los migrantes han formado asociaciones en Estados Unidos y mantienen interés en la política guatemalteca. De hecho los principales candidatos a la presidencia en 2007 viajaron a EEUU para reunirse con miembros de dichas asociaciones. ${ }^{14}$

Según el Banco de Guatemala, los riesgos de inflación se han hecho más latentes, por factores como el incremento en los precios del petróleo y del maíz. La inflación interanual a octubre 2007 (respecto al mismo mes en 2006) alcanzó 7,72\%. El crédito bancario al sector privado se desaceleró gradualmente, pasando de 28,8\% en diciembre de 2006 a 26,5\% en noviembre del 2007. Las exportaciones mostraron el mayor dinamismo observado en los

\footnotetext{
PRONACOM: www.pronacom.org

El Periódico, "CEPAL: Guatemala creció un 5,6 por ciento este año".

Ibid, Instituto Nacional de Estadística.

12 Banco de Guatemala. Desempeño Macroeconómico reciente y estimación de cierre 2007. Guatemala, noviembre, 2007. Se estima que hay mas de 1.2 millones de guatemaltecos en 25 estados de EE.UU. Según las previsiones económicas, en 2007 el monto por remesas al país superaría los US\$ 4 mil millones.

13 En 2007 fueron deportados 23.062 guatemaltecos indocumentados, lo que superó la cifra de 18.305 del 2006. Prensa Libre, "EE.UU. deportó a 392 guatemaltecos en primera semana de 2008."

14 Uno de los temas que los migrantes han buscado repetidamente es que se establezca el voto en el extranjero, el cual no existe en la actual legislación electoral.
} 
últimos diez años; el valor de las mismas ascendió a US\$ 5.253,5 millones, en comparación con US\$ 4.499,4 millones en el año anterior. ${ }^{15}$

Otro aspecto a destacar es que como parte de la crisis bancaria que estalló en octubre 2006 (ver Anuario 2006) se produjo en enero de 2007 la quiebra del Banco de Comercio, la cual afectó a cerca de 7.000 inversionistas. En contraste, durante el año se produjo la fusión de seis bancos, buscando consolidar su posición en el mercado financiero. Finalmente, como producto de la Ley Antievasión que entró en vigencia en el año 2006, durante 2007 se incrementó la recaudación tributaria en el país en un 15,8\% respecto a 2006. Ello significó una carga tributaria récord, en torno al 12,3\% respecto del Producto Interno Bruto (PIB). En total se recaudó el equivalente a unos US\$ 4.700 millones durante 2007.16

En conclusión, la situación macroeconómica en 2007 fue favorable, pero el crecimiento económico continúa sin tener un impacto visible en las condiciones de pobreza y desigualdad existentes.

\section{Coyuntura subregional e internacional}

Los países centroamericanos trataron en 2007 de implementar medidas de apertura comercial que logren generar más inversión en la subregión e incrementar los niveles de exportación. A principios de diciembre 2007 los presidentes centroamericanos firmaron un convenio marco para el establecimiento de una unión aduanera con el fin de crear en el mediano plazo una zona de libre comercio. ${ }^{17}$ Ello coadyuva a la negociación conjunta que se realiza con la Unión Europea para la firma de un Acuerdo de Asociación. El proyecto se presenta como algo más que un TLC tradicional e incluye un componente de diálogo político y cooperación que excede el aspecto económico. El Acuerdo será negociado por los dos bloques (no país por país).

En 2007 Guatemala fue país anfitrión de una serie de eventos de trascendencia regional e internacional. ${ }^{18}$ Por otro lado, el país estuvo bajo el escrutinio internacional debido por un lado a la realización de las elecciones, a las cuales asistieron numerosos observadores internacionales, y por otro por la discusión generada en torno a la creación de la CICIG y la nueva Ley de Adopciones. En el caso de las elecciones, los observadores jugaron un papel

15 Ibid, Banco de Guatemala. El sector de la maquila fue el que registró mayor ingreso del total de las exportaciones (US\$ 1.763,4 millones). En cuanto al destino de las exportaciones, el 43,5\% fue a EE.UU. y el $18,2 \%$ a Centroamérica.

16 El incremento fue positivo, sin embargo Guatemala sigue teniendo una de las cargas tributarias más bajas de América Latina.

17 Prensa Libre, "Istmo acuerda unión."

18 Entre esos eventos destacan la 48 Reunión Anual del Banco Interamericano de Desarrollo (BID), la XXXI Cumbre del Sistema de Integración Centroamericana (SICA), la Asamblea del Comité Olímpico Internacional y la III Cumbre Continental de Pueblos y Nacionalidades Indígenas. También se recibió la visita de personalidades internacionales, incluyendo el Rey Juan Carlos de España, la presidenta de Chile, Michelle Bachelet, el presidente de Rusia, Vladimir Putin, el de México, Felipe Calderón y el de Corea del Sur, Roh Moohyun. La visita más controversial fue la del presidente norteamericano George W. Bush en marzo de 2007, la cual generó protestas y manifestaciones de sectores opuestos al tratado de libre comercio con ese país y de aquellos descontentos con la deportación de guatemaltecos indocumentados y con ciertas acciones de política internacional de Estados Unidos. 
favorable y al final del proceso reconocieron la validez del mismo. En el caso de la CICIG y la nueva Ley de Adopciones, la presión internacional contribuyó significativamente a alcanzar acuerdos entre los partidos políticos.

\section{Coyuntura política}

El ambiente político en todo el país fue marcado por la dinámica de las Elecciones Generales realizadas en septiembre. Luego de la convocatoria oficial hecha por el Tribunal Supremo Electoral (TSE) el 2 de mayo, los partidos políticos -que habían empezado una temprana campaña electoral desde el año 2006 pese a las prohibiciones (ver Anuario 2006)- se concentraron en el primer semestre en definir las candidaturas a los diversos cargos de elección popular y en el segundo semestre del año a buscar el voto ciudadano. El Congreso aprobó un presupuesto de 409 millones de quetzales, luego de un proceso de negociación con el TSE. ${ }^{19}$

El proceso electoral de 2007 tuvo una serie de novedades resultantes de las reformas a la Ley Electoral y de Partidos Políticos aprobadas en 2004 y 2006. Las reformas más relevantes se relacionaron con el acortamiento de los plazos de todas las fases del proceso electoral, el control y fiscalización del financiamiento público y privado de los partidos políticos, especialmente el destinado para la campaña electoral y la descentralización de los centros de votación. Esto último obligó al TSE a colocar mesas electorales adicionales en lugares aislados del país, cuyos habitantes en elecciones anteriores tenían que viajar por largas horas para poder emitir su voto. ${ }^{20}$

El proceso electoral avanzó acompañado de expresiones de la apatía ciudadana, ofrecimientos de los partidos políticos participantes en la contienda, enfrentamientos verbales entre los mismos y casos de aparente violencia política. Sin embargo, no quedó claro si los asesinatos de más de 50 personas vinculadas a partidos políticos, en particular previo a la primera vuelta electoral, fueron producto de la delincuencia común o tuvieron origen político. Los observadores internacionales se mostraron confundidos respecto al origen de los mismos. Por un lado observadores de la Unión Europea señalaron su preocupación por el aparente repunte de la violencia político-electoral, pero en una entrevista con un periódico local el Jefe de la Misión de Observación Electoral de la Organización de Estados Americanos (OEA) indicó lo siguiente: ${ }^{21}$

En Guatemala el Tribunal Supremo Electoral está formado por cinco Magistrados titulares independientes y sus respectivos suplentes (no vinculados a los partidos políticos), electos por el Congreso de la República por un período de seis años, los cuales son seleccionados de una nómina de cuarenta candidatos propuestos por la Comisión de Postulación. Tal Comisión es conformada por el Rector de la universidad nacional, un representante de las universidades privadas, un representante del Colegio de Abogados de Guatemala, el Decano de la Facultad de Derecho de la universidad nacional (Universidad de San Carlos) y un representante de todos los Decanos de las Facultades de Derecho de las universidades privadas.

20 Las reformas determinaron que el TSE debía colocar mesas electorales en aquellas poblaciones con más de 500 habitantes.

21 El Periódico, "Hay aspectos positivos”, entrevista a Diego García Sayán, Jefe de la Misión de Observación de las elecciones de la Organización de Estados Americanos, OEA. Ver también BBC News, "Guatemala campaign deaths mount" y "EU alarm at Guatemala violence." Ver también Miami Herald, "Guatemala's Candidates Run the Gamut." 
"En la primera vuelta hubo muchas denuncias públicas de supuestos crimenes con motivaciones politicas. Nosotros sostuvimos una tesis homogénea sobre eso diciendo que las motivaciones de los actos criminales no se podían presuponer ni eran materia de análisis político especulativo, sino que tenían que sacarse conclusiones sobre la motivación a partir de la investigación criminal. Las investigaciones están en curso, pero más allá que fueran o no homicidios con motivación política, de hecho hubo una percepción en sectores de la ciudadanía y de la prensa de que así era."

Los temas principales de la campaña fueron la seguridad, la economía y algunos temas sociales como educación, salud y vivienda. Los ciudadanos manifestaron su descontento por la campaña negra en particular entre los candidatos identificados por las encuestas con mayores posibilidades de obtener el voto popular. ${ }^{22} \mathrm{Al}$ final de cuentas, luego de varios meses de campaña negra y el temor de violentas reacciones de descontento hacia los resultados, las elecciones en sí resultaron ser ordenadas y pacíficas.

Las tensiones se intensificaron en el período previo a la segunda vuelta electoral prevista para el 4 de noviembre entre los dos candidatos presidenciales que obtuvieron la mayoría de votos en la primera vuelta, Otto Pérez Molina y Álvaro Colom. Sin embargo, el proceso se llevó a cabo en forma pacífica. El TSE realizó un rápido conteo de votos y luego de conocerse el triunfo de Colom, el candidato opositor reconoció su derrota y el candidato ganador se mostró conciliador con la oposición y con diversos sectores. Los observadores internacionales reconocieron la fiabilidad de las elecciones realizadas y elogiaron los aspectos técnicos de las mismas. La misión de observación electoral de la Unión Europa señaló que las elecciones de segunda vuelta fueron un "ejemplo magnífico" para el mundo, por la buena organización y transparencia. ${ }^{23}$

Además de los observadores internacionales, numerosas organizaciones sociales guatemaltecas se constituyeron en observadores internos. El TSE acreditó en 2007 a unas 70 mil personas, entre voluntarios, misiones internacionales y periodistas nacionales y extranjeros, para verificar el proceso del 9 de septiembre, convirtiéndose en el proceso electoral más observado de la historia del país. ${ }^{24}$

Los últimos dos meses del año se caracterizaron por un traspaso de mando calmado y eficiente entre la administración saliente de Óscar Berger y la entrante de Álvaro Colom, proceso conducido por el vicepresidente saliente, Eduardo Stein. Adicionalmente, dada la anunciada apertura del candidato ganador a escuchar a diversos sectores, se dieron intensas negociaciones a efecto de conformar el nuevo gabinete de gobierno que tomó posesión el 14 de enero. ${ }^{25}$

23 El jefe de esa misión, el eurodiputado alemán Wolfgang Kreissl-Dörfler, dijo en una rueda de prensa durante la presentación del informe preliminar de observación, que ha visto 'otras elecciones no tan buenas como éstas. Fueron un ejemplo magnífico para América Latina y para el mundo.' Univision.com, “UE dice que elecciones de Guatemala fueron un ejemplo magnífico para el mundo." Sin embargo, los observadores también hicieron ver los aspectos negativos del proceso, en particular la violencia electoral.

24 La Prensa, "El proceso electoral más observado."

25 Colom había anticipado que presentaría a su nuevo gabinete de gobierno el 1 de diciembre, pero la dificultad de llegar a acuerdos sobre los nombramientos con diversos sectores, incluyendo a los miembros de su partido, atrasó el proceso. 


\section{CAMBIOS INSTITUCIONALES Y CAMBIOS SUBSTANCIALES EN POLÍTICAS PÚBLICAS}

\section{Políticas domésticas}

En el año 2006 se inició en el país un proceso de discusión y diálogo para lograr consensos en la definición de políticas públicas intertemporales. En ese contexto surgió un pacto nacional, llamado Plan Visión de País, con el fin de marcar una línea consensuada de acción, respetando ideologías partidarias y las posiciones de diferentes grupos sociales (ver Anuario 2006). Se negociaron pactos en cuatro áreas: seguridad, educación, salud y desarrollo rural, todo ello enmarcado en los ejes económicos, fiscales y de multiculturalidad. Los partidos políticos se comprometieron a transformar en 2007 los cuatro acuerdos en leyes que facilitarán la implementación de políticas públicas en esas materias, con vistas a un mayor desarrollo para el año 2020. Sin embargo, en el Congreso de la República el trabajo legislativo para llevar a cabo la aprobación de los acuerdos se estancó debido en gran parte a la campaña electoral, por lo que las cuatro leyes marco sobre educación, seguridad, salud y desarrollo social del Plan Visión de País quedaron engavetadas.

En otro orden de ideas, en los últimos meses del 2007 se oficializó la discusión de un incremento al salario mínimo, tema que se venía discutiendo entre patrones y trabajadores desde varios meses atrás en la Comisión Nacional del Salario (CNS), donde tanto patronos como trabajadores discutieron sobre el incremento. A finales de diciembre, el presidente Óscar Berger aprobó el Acuerdo Gubernativo 625-2007 que concedió un incremento del $5 \%$ diario a partir del 1 de enero, 2008; las organizaciones de trabajadores y campesinas criticaron el bajo monto del incremento aprobado. ${ }^{26}$

En el balance general, la principal crítica hacia la administración de gobierno saliente ${ }^{27}$ fue el no haber implementado una efectiva política de seguridad y haber permitido la continuada penetración de las mafias organizadas en las instituciones encargadas de la seguridad pública. El desalojo violento de campesinos que ocuparon tierras y la incapacidad para detener la violencia contra las mujeres fueron también criticados. En el lado positivo, pese a los conflictos con el sector magisterial, la política educativa logró tener cobertura completa para los seis años de primaria. Otro aspecto favorable fue la implementación de obras de infraestructura, incluyendo la total remodelación del aeropuerto internacional. ${ }^{28}$

\section{Política internacional}

Entre los hechos relevantes de política internacional destacó en 2007 el establecimiento de relaciones diplomáticas con Corea del Norte y acercamientos con India para el establecimiento de una Embajada guatemalteca en ese país. Guatemala continuó

\footnotetext{
26 Prensa Libre, "Aumenta Salario Mínimo".

27 La administración de Oscar Berger cubrió el período del 14 de enero, 2004 al 14 de enero, 2008.

28 Comentaristas políticos señalaron que uno de los mayores logros no tangibles de la administración saliente fue el reencauzar el proceso político en el país y el restablecer -aún si sólo parcialmente- la confianza en las instituciones de gobierno, la cual había sido afectada seriamente por altos niveles de corrupción y confrontación durante el gobierno precedente del Frente Republicano Guatemalteco (FRG).
} 
contribuyendo con contingentes en misiones de paz financiadas por las Naciones Unidas en la República Democrática del Congo y en Haití. En materia internacional también se debatió acerca de la integración del presidente y el vicepresidente salientes al Parlamento Centroamericano. ${ }^{29}$ Finalmente, la comunidad internacional vio favorablemente que el mandatario saliente, Óscar Berger, invitara al nuevo presidente electo, Álvaro Colom, a acompañarlo a la Cumbre Iberoamericana realizada en Chile en noviembre, 2007. El gesto fue visto como un acto de madurez política en una sociedad donde la confrontación y no la conciliación han sido la norma.

\section{RESULTADOS DE ELECCIONES NACIONALES}

Por sexta vez, desde el inicio de la apertura democrática en el año de 1985, se realizó un proceso de Elecciones Generales (presidenciales, legislativas y municipales), esta vez para elegir a las autoridades que regirán al país durante el periodo 2008-2012. El TSE estableció el 9 de septiembre como fecha para las Elecciones Generales y el 4 de noviembre como fecha para una eventual segunda ronda electoral entre los dos candidatos finalistas. ${ }^{30}$

Como en ocasiones anteriores, una de las principales características del proceso electoral fue el elevado número de partidos políticos que participaron en la contienda. Catorce partidos presentaron candidatos a la Presidencia de la República, diputados y corporaciones municipales, y dos únicamente presentaron candidatos a diputados y corporaciones municipales. La fragmentación de la izquierda en varios partidos débiles fue manifiesta, aunque también la derecha sufrió divisiones. Guatemala es actualmente el país latinoamericano con mayor nivel de fragmentación partidaria (ver Altman en Anuario 2006). Con relación al espectro ideológico, la mayoría de partidos participantes pueden considerarse de derecha o centro-derecha, aunque en Guatemala los partidos son más bien personalistas y la mayoría no siguen una línea ideológica clara. Los únicos partidos claramente de izquierda fueron la anterior guerrilla en la coalición denominada URNGMaíz, la ANN y Encuentro por Guatemala (EG). En el centro-izquierda se ubica al partido ganador, la Unidad Nacional de la Esperanza (UNE), cuyo líder se ha autoidentificado como social-demócrata.

Según lo establecido por ese organismo los ex presidentes y ex vicepresidentes centroamericanos pasan a ser diputados centroamericanos durante el período inmediato posterior a su gestión de gobierno. El Parlamento Centroamericano es objeto de crítica de algunos sectores en Guatemala, que aducen que éste no cumple con objetivos de beneficio nacional ni regional. Los mandatarios salientes presentaron una consulta a la Corte de Constitucionalidad para determinar si deberían o no integrarse al mismo. En enero 2008 el presidente y el vicepresidente salientes Óscar Berger y Eduardo Stein, anunciaron que no se integrarán al Parlamento Centroamericano.

30 Según los artículos 201, 202 y 203 de la Ley Electoral y de Partidos Políticos vigente (1985), la elección presidencial se determina por mayoría absoluta, con una segunda vuelta si ninguno de los candidatos obtiene el $51 \%$ del voto en la primera ronda. Las asignación de curules en el Congreso se determina por un sistema de representación proporcional de minorías. Las elecciones de alcaldes y síndicos se rigen por un sistema de mayoría relativa, mientras que elecciones de concejales para las corporaciones municipales se rigen por el método de representación proporcional de minorías. 
Con relación a los candidatos a la presidencia, fue importante la participación de la primera candidata indígena a la Presidencia de la República, Rigoberta Menchú. ${ }^{31}$ Aparte de Menchú, ninguno de los otros candidatos a la presidencia fue de origen Maya, y solamente hubo un candidato indígena a la vicepresidencia. Teniendo en cuenta la estructura partidaria y el financiamiento disponible, los únicos candidatos con posibilidades de obtener un número significativo de votos fueron el Ingeniero Álvaro Colom de UNE, quien había ocupado varios cargos públicos, destacando el haber sido Director del Fondo Nacional para la Paz (FONAPAZ); el ex general Otto Pérez, presidenciable del Partido Patriota, quien fue jefe de los servicios de inteligencia del Ejército ${ }^{32}$-aunque también formó parte activa de la comisión que negoció los acuerdos de paz- y el candidato del partido oficial, GANA, Alejandro Giammattei, quien fungió como Director General de Presidios durante la administración saliente de Óscar Berger.

En parte como producto de las nuevas reformas a la Ley Electoral y de Partidos Políticos, el TSE incrementó y descentralizó el número de centros de votación, habiéndose duplicado el número de Juntas Receptoras de Votos en el país. El padrón electoral llegó a 5.990.029 ciudadanos aptos para sufragar el voto. De estos casi seis millones de guatemaltecos, más de 3,5 millones emitieron su voto en la primera vuelta electoral, representando un $60,20 \%$, una de las tasas más altas de participación en años recientes, tal como se observa en el Gráfico $1 .{ }^{33}$ Destaca que los porcentajes de concurrencia a las urnas en algunos lugares en donde por primera vez se colocaron mesas receptoras de votos, en particular zonas rurales indígenas, llegó al 90 por ciento. ${ }^{34}$ Debido a que ningún binomio presidencial obtuvo la mayoría absoluta en las elecciones presidenciales, se llevó a cabo una segunda vuelta el 4 de noviembre, en donde la participación descendió por debajo de los tres millones, lo que representó un $48,34 \%$ de los empadronados. ${ }^{35}$

31 Desde 1985, siete han sido las mujeres postuladas para formar un binomio presidencial. Tres como candidatas a la presidencia y cinco como candidatas a la vicepresidencia. Las tres candidatas presidenciales han sido Rigoberta Menchú en 2007, Flor de María Alvarado de Solís en 1995 por el FDP, , y Catalina Soberanis en 1999 por el FDNG. Respecto a las candidaturas a la vicepresidencia, en 1990 la coalición PSD- AP5 postuló a Araceli Conde de Paiz; en 1999, hubo dos candidatas vicepresidenciales, Arabella Castro por el PAN y Raquel Blandón por la coalición LOV-UD; en el 2003 el partido DIA postuló a Gladys Maritza Ruiz; en el 2007 el colectivo URNG-Maíz postuló a Walda Barrios.

32 Pérez fungió como Director de Inteligencia Militar (G2) entre 1991 y 1993 y como Jefe del Estado Mayor Presidencial (EMP) durante los años 1993 a 1996.

33 Cabe recordar que el voto en Guatemala no es obligatorio según lo establecido en la Constitución de la República de 1985.

34 El Periódico, "Hay aspectos positivos”, entrevista a Diego García Sayán.

35 Desde el inicio de la apertura democrática en 1985, la participación electoral se reduce notablemente en la segunda vuelta electoral, debido en parte a que en ésta no se eligen autoridades locales. Resultados Electorales por el Tribunal Supremo Electoral, www.tse.org.gt. 
Gráfico 1: Participación ciudadana en Elecciones Generales 1985-2007 en Guatemala

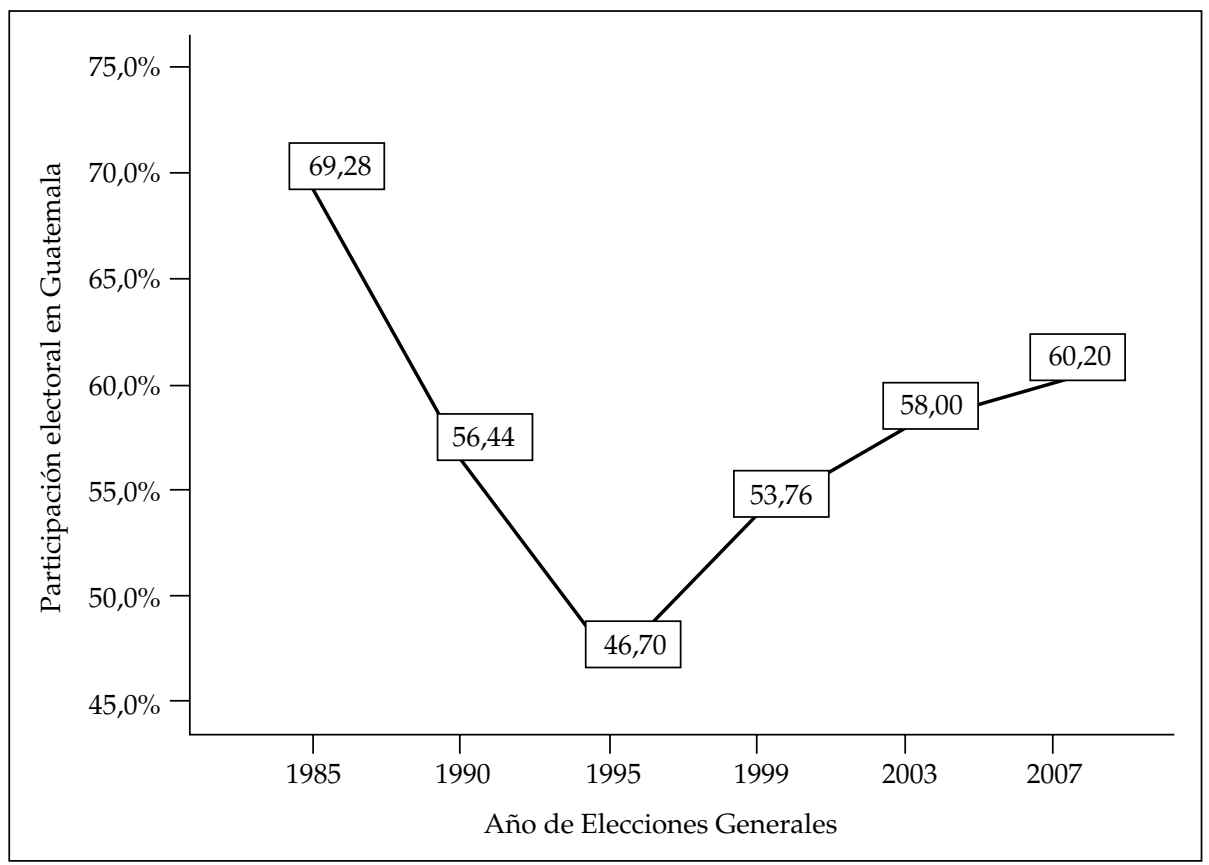

Fuente: elaboración de autoras con base en datos del TSE.

La Tabla 2 muestra un resumen de la participación ciudadana en las elecciones de 2007. Cabe resaltar el alto número de votos nulos o en blanco, que en su conjunto representaron un porcentaje mayor al obtenido por once de los catorce candidatos presidenciales que participaron en la elección. ${ }^{36}$

Tabla 2: Participación ciudadana en Elecciones Generales de 2007 en Guatemala

\begin{tabular}{|c|c|c|c|c|c|c|c|c|c|}
\hline & $\begin{array}{c}\text { Total de } \\
\text { Empadronados }\end{array}$ & Participación & $\%$ & $\begin{array}{c}\text { Votos } \\
\text { Válidos }\end{array}$ & $\begin{array}{l}\% \\
(1)\end{array}$ & $\begin{array}{l}\text { Votos } \\
\text { Nulos }\end{array}$ & $\begin{array}{l}\% \\
\text { (2) }\end{array}$ & $\begin{array}{l}\text { Votos } \\
\text { Blancos }\end{array}$ & $\begin{array}{l}\% \\
\text { (2) }\end{array}$ \\
\hline $1^{\text {a }}$. Vuelta & & 3.615 .867 & 60,22 & 3.278 .949 & 90,68 & 207.734 & 5,75 & 129.184 & 3,57 \\
\hline $2^{\mathrm{a}}$. Vuelta & 5.990 .029 & 2.895 .827 & 48,34 & 2.744 .042 & 94,76 & 101.196 & 3,49 & 50.589 & 1,75 \\
\hline
\end{tabular}

Fuente: Elaboración del DISOP/ASIES con datos del TSE.

(1) Porcentaje respecto a los ciudadanos empadronados.

(2) Porcentaje respecto a los votos emitidos.

36 El fenómeno del voto nulo o blanco no se ha analizado a nivel académico en Guatemala, pero es un tema importante dado el alto porcentaje de votos anulados o dejados en blanco. Se ha especulado que éste puede ser producto del descontento con el sistema político, pero también de la confusión de los electores que tienen que marcar boletas diferentes en cada Elección General (presidente, diputados distritales, diputados nacionales, autoridades locales y en anteriores ocasiones diputados al Parlamento Centroamericano). 


\section{Elección presidencial}

En lo que respecta a la elección presidencial, en la primera vuelta el partido Unidad Nacional de la Esperanza (UNE), que postuló al Ingeniero Álvaro Colom, obtuvo el mayor porcentaje de votos válidos $(28,25 \%)$. El Partido Patriota (PP), que postuló al ex general Otto Pérez adquirió la segunda posición en la primera vuelta, obteniendo el $23,54 \%$ del total de votos. Al no haber obtenido ninguno de los partidos la mayoría absoluta, se hizo necesaria la realización de una segunda ronda electoral a la cual pasaron los dos candidatos con mayor porcentaje de votos, Colom y Pérez. El partido de gobierno GANA logró ubicarse en la tercera posición, obteniendo el $17,23 \%$ de los votos, con una distancia considerable del primer lugar (una diferencia de once puntos porcentuales). En el cuarto lugar se ubicó el partido CASA con 7,45\% del total de votos. El FRG obtuvo la quinta posición con 7,30\%. Los otros partidos obtuvieron menos del $5 \%$ de los votos válidos. El partido Encuentro por Guatemala, que postuló a Rigoberta Menchú, obtuvo sólo el 3,06\% de los votos. ${ }^{37}$

Tres de los partidos que postularon candidatos en 2007 (DIA, DCG y ANN) desaparecieron automáticamente al no haber obtenido en los resultados electorales el mínimo de $4 \%$ de los votos totales o al menos una diputación al Congreso. El partido Democracia Cristiana (DCG) era uno de los partidos con línea ideológica más definida y con mayor tradición en el país, ya que fue conformado desde mediados de los años 60; sin embargo, sufrió un importante desgaste cuando ejerció el poder en 1986-1989, del que nunca logró recuperarse. La ANN por otro lado fue el primer partido de izquierda de extracción popular que participó en las elecciones desde la apertura democrática. El detalle de los resultados de la primera vuelta se observa en la Tabla 3.

Los dos meses que transcurrieron entre la primera y la segunda vuelta electoral continuaron siendo marcados por las campañas negras entre los dos candidatos finalistas y por la búsqueda de apoyos y la negociación de los dos partidos ganadores con el resto de partidos y con otros grupos sociales. ${ }^{38} \mathrm{La}$ violencia política-electoral, aunque disminuyó, todavía golpeó a ambos partidos. El candidato del PP, cuyo lema de campaña era "mano dura" enfatizó la necesidad combatir enérgicamente la delincuencia y el crimen organizado, lo que le generó apoyo en las áreas urbanas del país, incluyendo la capital. El candidato de la UNE por su lado enfatizó que la delincuencia debería combatirse con inteligencia y que por tanto la lucha contra la misma también debía incluir la mejora de la situación de pobreza de la mayoría de guatemaltecos. El mensaje de este último tuvo mayor eco en las áreas rurales de Guatemala, en las cuales la principal preocupación es de índole

37 Posteriormente a las elecciones, Menchú reconoció la validez de los resultados, pero señaló que el sistema electoral guatemalteco adolece de una serie de obstáculos que no permiten la participación de candidatos con poco financiamiento y débil estructura organizativa. Lacey, Marc. “Complex Defeat for Nobel Winner in Guatemala", New York Times.

38 Finalmente ni el PP ni la UNE concretaron negociaciones institucionales con otros partidos políticos. Sin embargo, dirigentes y ex candidatos de varios partidos a nivel personal ofrecieron su apoyo a uno u otro partido. Resalta el caso del partido oficial GANA en donde se generó una importante división interna debido al apoyo que el ex candidato presidencial (Giammattei) y algunos miembros del partido dieron al PP, mientras que otro grupo apoyó a la UNE. En el caso del FRG, importantes líderes a nivel local apoyaron a uno u otro candidato. Por el lado de agrupaciones sociales de importancia, el movimiento cooperativo y los maestros del sistema oficial apoyaron a Colom. 
Tabla 3: Resultados de la primera vuelta de la elección presidencial en Guatemala (9 de septiembre, 2007)

\begin{tabular}{|c|c|c|c|}
\hline Partido Político & $\begin{array}{c}\text { Candidatos a la Presidencia } \\
\text { y Vicepresidencia }\end{array}$ & Votos obtenidos & Porcentaje \\
\hline $\begin{array}{l}\text { 1. Unidad Nacional } \\
\text { de la Esperanza (UNE) }\end{array}$ & $\begin{array}{l}\text { Álvaro Colom } \\
\text { Rafael Espada }\end{array}$ & 926.236 & 28,25 \\
\hline 2. Partido Patriota (PP) & $\begin{array}{l}\text { Otto Pérez } \\
\text { Ricardo Castillo }\end{array}$ & 771.813 & 23,54 \\
\hline $\begin{array}{l}\text { 3. Gran Alianza } \\
\text { Nacional (GANA) }\end{array}$ & $\begin{array}{l}\text { Alejandro Giammattei } \\
\text { Alfredo Vila }\end{array}$ & 565.017 & 17,23 \\
\hline $\begin{array}{l}\text { 4. Centro de Acción } \\
\text { Social (CASA) }\end{array}$ & $\begin{array}{l}\text { Eduardo Suger } \\
\text { Edwin Lobos }\end{array}$ & 244.373 & 7,45 \\
\hline $\begin{array}{l}\text { 5. Frente Republicano } \\
\text { Guatemalteco (FRG) }\end{array}$ & $\begin{array}{l}\text { Luis Rabbé } \\
\text { Haroldo Quej }\end{array}$ & 239.204 & 7,30 \\
\hline $\begin{array}{l}\text { 6. Unión del Cambio } \\
\text { Nacionalista (UCN) }\end{array}$ & $\begin{array}{l}\text { Mario Estrada } \\
\text { Mario Torres }\end{array}$ & 103.695 & 3,16 \\
\hline $\begin{array}{l}\text { 7. Encuentro por } \\
\text { Guatemala (EG) }\end{array}$ & $\begin{array}{l}\text { Rigoberta Menchú } \\
\text { Luis Montenegro }\end{array}$ & 100.365 & 3,06 \\
\hline 8. Partido Unionista (PU) & $\begin{array}{l}\text { Fritz García-Gallont } \\
\text { Enrique Godoy }\end{array}$ & 95.280 & 2,91 \\
\hline $\begin{array}{l}\text { 9. Partido de Avanzada } \\
\text { Nacional (PAN) }\end{array}$ & $\begin{array}{l}\text { Óscar Castañeda } \\
\text { Roger Valenzuela }\end{array}$ & 83.369 & 2,54 \\
\hline 10. URNG-MAIZ & $\begin{array}{l}\text { Miguel Ángel Sandoval } \\
\text { Walda Barrios }\end{array}$ & 70.208 & 2,14 \\
\hline 11. Unión Democrática (UD) & $\begin{array}{l}\text { Manuel Conde } \\
\text { Juan Manríquez }\end{array}$ & 24.893 & 0,76 \\
\hline $\begin{array}{l}\text { 12. Alianza Nueva } \\
\text { Nación (ANN) }\end{array}$ & $\begin{array}{l}\text { Pablo Monsanto } \\
\text { Mariano Portillo }\end{array}$ & 19.640 & 0,60 \\
\hline 13. DÍA & $\begin{array}{l}\text { Héctor Rosales } \\
\text { Carlos Pérez }\end{array}$ & 18.395 & 0,56 \\
\hline $\begin{array}{l}\text { 14. Democracia Cristiana } \\
\text { Guatemalteca (DCG) }\end{array}$ & $\begin{array}{l}\text { Marco Cerezo } \\
\text { Pablo Ramírez }\end{array}$ & 16.461 & 0,50 \\
\hline Total de votos válidos & & 3.278 .949 & 100,00 \\
\hline Total de votos blancos & & 129.184 & 3,57 \\
\hline Total de votos nulos & & 207.734 & 5,75 \\
\hline Total de votos emitidos & & 3.615 .867 & - \\
\hline
\end{tabular}

Fuente: Elaboración de autoras según datos del TSE. 
social, a diferencia de la capital en la cual la mayor preocupación es la criminalidad. ${ }^{39}$ Los resultados de la segunda vuelta electoral presidencial le dieron el triunfo a Álvaro Colom, candidato de la UNE, quien obtuvo 1.449 .349 votos a nivel nacional equivalente al $52,82 \%$ del total de votos válidos; Otto Pérez Molina obtuvo 1.294 .693 votos, equivalente a 47,18\%. El detalle de los resultados se observa en la Tabla 4.

La mayoría de las encuestas habían anticipado un triunfo de Pérez, por lo que su derrota pareció sorpresiva a muchos. El resultado final de las elecciones presidenciales de 2007 en Guatemala tuvo un importante componente geográfico. Pérez ganó en la capital guatemalteca, en donde obtuvo el 65\% de los votos. Sin embargo, análisis posteriores indicaron que las mediciones de opinión pública no captaron a cabalidad el voto del área rural, el cual fue determinante para el triunfo de Colom. Al final de cuentas, Colom ganó en 20 de los 22 departamentos del país. Estas son las primeras elecciones en Guatemala en las que un candidato obtiene la presidencia sin haber ganado el voto capitalino. Se ha señalado que la descentralización de las mesas electorales en el proceso de 2007 pudo haber contribuido a este cambio. ${ }^{40}$

Tabla 4: Resultados de la segunda vuelta de la elección presidencial en Guatemala (4 de noviembre, 2007)

\begin{tabular}{lcc}
\hline \multicolumn{1}{c}{ Partido Político } & Votos obtenidos & Porcentaje \\
\hline PP & 1.294 .693 & 47,18 \\
UNE & 1.449 .349 & 52,82 \\
Votos Válidos & 2.744 .042 & 100,00 \\
Votos Blancos & 50.589 & 1,75 \\
Votos Nulos & 101.196 & 3,49 \\
Votos Emitidos & 2.895 .827 & - \\
\hline
\end{tabular}

Fuente: Elaboración del DISOP/ASIES con datos del TSE.

\section{Elecciones legislativas}

Desde la apertura democrática en 1985 el Congreso de la República ha estado integrado por un alto número de partidos políticos y las elecciones de 2007 siguieron dicho patrón. 158 diputados provenientes de once fuerzas políticas fueron electos el 9 de septiembre. Los partidos UNE, GANA y PP, los tres partidos dominantes en la elección presidencial, ejercieron un claro predominio en la elección parlamentaria; no obstante, muchos ciudadanos optaron por emitir un voto dividido, por lo cual la UNE no contará con una bancada mayoritaria en el nuevo Congreso. También resalta que el PP a pesar de haberse constituido

39 A nivel internacional, la candidatura de Pérez fue vista como un regreso al pasado, mientras que Colom fue percibido como un técnico con visión social. Ver Roig-Franzia, Manuel, “Choosing a Future From Tainted Pasts", Washington Post.

40 El área metropolitana incluye a la capital y los municipios aledaños, que en total conforman alrededor de un $25 \%$ de los votantes registrados (empadronados). 
como la segunda fuerza en las elecciones presidenciales fue relegado al tercer lugar en la elección legislativa, precedido por el partido de gobierno (GANA). Luego de la elección, dichos partidos se constituyen en las fuerzas políticas mayoritarias del país, concentrando casi tres cuartas partes $(74,05 \%)$ del total de curules del Organismo Legislativo, como se observa en el Gráfico 2 y con mayor detalle en la Tabla 5.

Gráfico 2: Composición del Congreso luego de las elecciones legislativas de 2007 en Guatemala

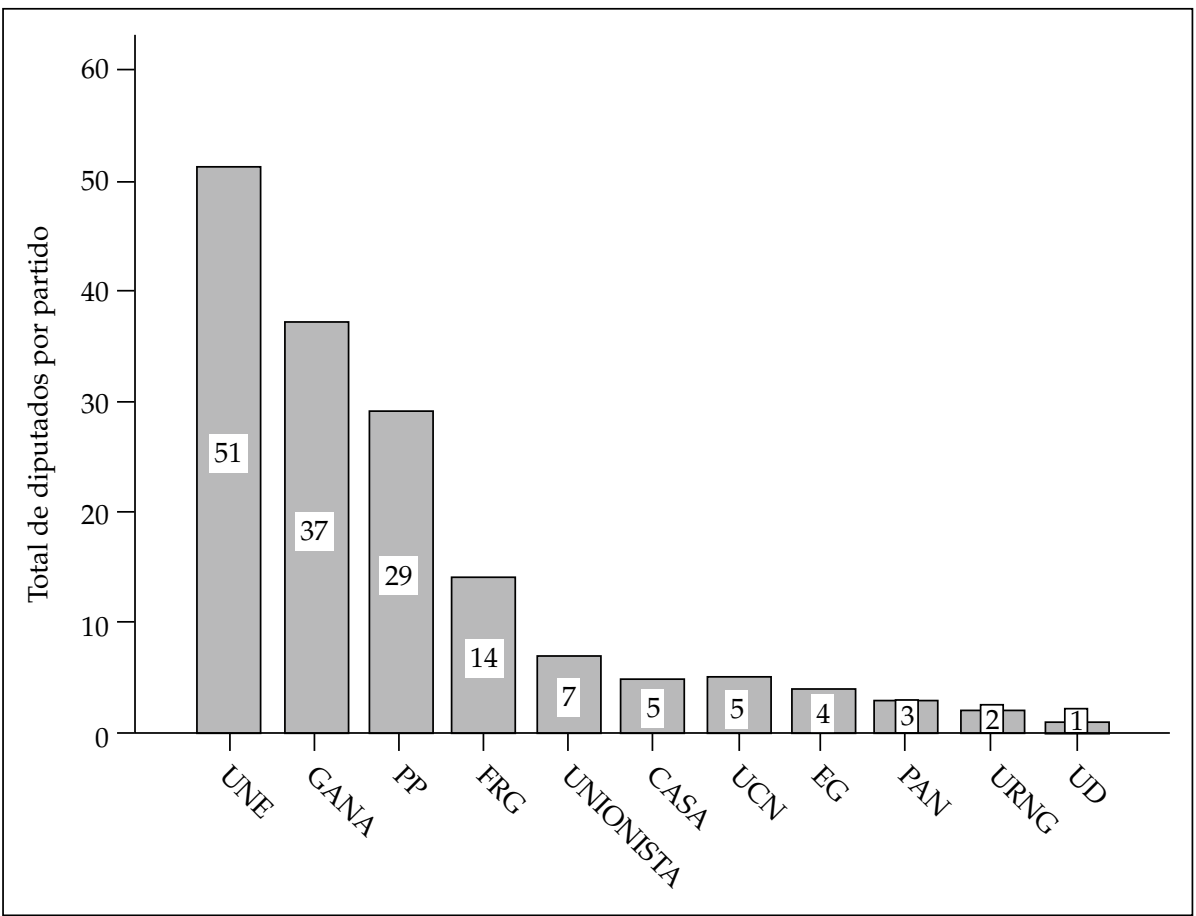

Fuente: Elaboración de autoras con base en datos del TSE.

Tabla 5: Distribución de curules en el Congreso guatemalteco luego de las elecciones de 2007

\begin{tabular}{llcccc}
\hline & & Lista Nacional & Distritales & Total & Porcentaje del total \\
\hline 1. & UNE & 8 & 43 & 51 & 32,2 \\
2. & GANA & 6 & 31 & 37 & 23,4 \\
3. & PATRIOTA & 6 & 23 & 29 & 18,4 \\
4. & FRG & 3 & 11 & 14 & 8,9 \\
5. & UNIONISTA & 2 & 5 & 7 & 4,4 \\
6. & CASA & 1 & 4 & 5 & 3,2 \\
7. & UCN & 1 & 4 & 5 & 3,2
\end{tabular}




\begin{tabular}{rlcccc}
\hline & Lista Nacional & Distritales & Total & Porcentaje del total \\
\hline 8. & EG & 2 & 2 & 4 & 2,5 \\
9. PAN & 1 & 2 & 3 & 1,9 \\
10. URNG & 1 & 1 & 2 & 1,3 \\
11. UD & - & 1 & 1 & 0,6 \\
TOTAL & 31 & 127 & 158 & 100,0 \\
\hline
\end{tabular}

Fuente: Elaboración de autoras con base en datos DISOP/ASIES y el TSE.

En cuanto a la composición ideológica del nuevo Congreso, 62\% de los diputados pertenecen a partidos políticos considerados de derecha, mientras que la izquierda obtuvo únicamente el 4\% (URNG y EG). El balance lo presenta el partido UNE, cuyo liderazgo es de línea social-demócrata. No obstante, la historia reciente ha mostrado que la mayoría de diputados guatemaltecos tiene una débil convicción ideológica al igual que una débil disciplina partidaria, y que sus votos en el Congreso siguen más bien otros criterios. Es por ello que es difícil anticipar coaliciones que duren todo el período. Las coaliciones con frecuencia se basan en la negociación de puestos a la Junta Directiva del Congreso y las comisiones legislativas, así como a la negociación de construcción de obras públicas.

Con respecto a la representación política de minorías en el nuevo Congreso, ni el número de mujeres ni de indígenas es significativo. El número de diputadas electas asciende a 19, equivalente al $12 \%$ del total de integrantes de ese Organismo, como se observa en la Tabla 6. Por otro lado, en las últimas elecciones fueron electos 15 diputados de origen Maya, lo que equivale al 9\% del total, como se observa en la Tabla 7. En ambos casos, el reducido número de representantes femeninas o indígenas está lejos de reflejar la composición de la población guatemalteca.

Tabla 6: Número de diputadas electas al Congreso en 2007

\begin{tabular}{lccc}
\hline Partido político & Lista Nacional & Distrital & Total \\
\hline UNE & 2 & 7 & 9 \\
GANA & 2 & 1 & 3 \\
PP & 1 & 2 & 3 \\
FRG & 1 & - & 1 \\
EG & 2 & - & 2 \\
CASA & - & 1 & 1 \\
TOTAL & 8 & 11 & 19 \\
\hline
\end{tabular}

Fuente: Elaboración del DISOP/ASIES según datos del TSE. 
Tabla 7: Número de diputados indígenas al Congreso en 2007

\begin{tabular}{lccc}
\hline Partido político & Lista Nacional & Distrital & Total \\
\hline UNE & - & 7 & 7 \\
PP & - & 3 & 3 \\
GANA & - & 1 & 1 \\
FRG & - & 1 & 1 \\
PU & - & 1 & 1 \\
EG & 1 & - & 1 \\
PAN & - & 1 & 1 \\
TOTAL & 1 & 14 & 15 \\
\hline
\end{tabular}

Fuente: Elaboración del DISOP/ASIES según datos del TSE.

\section{Elección de corporaciones municipales}

En las Elecciones Generales del 9 de septiembre los guatemaltecos eligieron 332 corporaciones municipales. El 68\% de las alcaldías fueron distribuidas entre tres organizaciones políticas (UNE, GANA y PP). El 38\% restante de las alcaldías quedó distribuido entre 12 partidos políticos y 19 Comités Cívicos Electorales. ${ }^{41}$ La UNE ganó casi un tercio (104) de las alcaldías, lo que corresponde al 31,33\% del total de corporaciones municipales a escala nacional, mostrando así un índice de eficiencia del 32,20\% de acuerdo al número de postulaciones realizadas. La GANA se constituyó como la segunda fuerza política a nivel municipal, habiendo obtenido 77 alcaldías, pero su índice de eficiencia fue regular $(24,29 \%)$, tomando en cuenta que postuló un total de 317 candidatos a alcaldes. El PP, pese a haber postulado alcaldes en casi todos los municipios del país (308 de 332), alcanzó una débil adjudicación de cargos en el ámbito municipal, logrando únicamente 39 alcaldías, siendo su índice de eficiencia del 12,66\%. La síntesis de los resultados de las elecciones municipales se observa en la Tabla 8.

Cabe destacar que a nivel de las elecciones municipales se da generalmente mayor diversidad étnica que en las elecciones legislativas. En los comicios de 2007 esta diversidad aumentó con relación a las elecciones de 2003. De las 332 alcaldías en todo el país, 129 fueron ganadas por candidatos indígenas, mientras que en 2003 fueron $123{ }^{42}$

41 Los Comités Cívicos Electorales son organizaciones políticas de carácter temporal que pueden postular candidatos a corporaciones municipales en su respectiva circunscripción geográfica.

42 Prensa Libre, "Con Poder." 
Tabla 8: Síntesis de los resultados municipales en las elecciones 2007 en Guatemala

\begin{tabular}{llcc}
\hline Partido & Alcaldes Electos & $\begin{array}{c}\text { Porcentaje del total de } \\
\text { alcaldías del país }\end{array}$ \\
\hline 1. & UNE & 104 & 31,33 \\
2. & GANA & 77 & 23,19 \\
3. & PP & 39 & 11,75 \\
4. & FRG & 23 & 6,93 \\
5. & PU & 24 & 7,23 \\
6. & PAN & 13 & 3,92 \\
7. & UCN & 12 & 3,61 \\
8. & URNG & 7 & 2,11 \\
9. & UD & 4 & 1,20 \\
10. & DIA & 3 & 0,90 \\
11. & ANN & 2 & 0,60 \\
12. & EG & 1 & 0,30 \\
13. CASA & DCG & 1 & 0,30 \\
14. & DCG & 0,30 \\
15. & El Frente & 1 & 0,60 \\
16. Comités Cívicos Electorales & 2 & 5,72 \\
TOTAL & 19 & 100,00 \\
\hline
\end{tabular}

Fuente: Elaboración del DISOP/ASIES según datos oficiales del TSE.

\section{PODER EJECUTIVO}

\section{Composición y rotación del gabinete en $\mathbf{2 0 0 7}$}

Durante el último año de gobierno del presidente Berger se evidenció cierto grado de "cansancio político" generándose un desgaste dentro de los Ministerios y dependencias del Organismo Ejecutivo. Dieciséis altos funcionarios del mismo renunciaron a sus cargos en 2007 y uno más fue destituido (el ministro de Gobernación). Algunos renunciaron por agotamiento o por nuevas oportunidades laborales-caso de los ministros de Energía, Salud y Finanzas-, sin embargo la gran mayoría buscó candidaturas para cargos públicos de elección popular, motivo por el cual legalmente debían dejar su puesto en el Ejecutivo.

Con relación a la composición del Organismo Ejecutivo, en la Tabla 9 se muestra quienes fueron los ministros del Gabinete en el último año de la administración Berger, así como los ministros que fungieron durante los cuatro años de gobierno. Cabe destacar que solamente dos de ellos, la ministra de Educación y el ministro de Ambiente y Recursos Naturales, permanecieron en los cargos a lo largo de los cuatro años. Los otros once ministerios fueron dirigidos por al menos dos personas durante el período. ${ }^{43}$

43 Cabe recordar que la coalición original que ganó las elecciones de 2003 GANA-PP-MNR, empezó a desmantelarse pocos meses después de haber tomado posesión. Para finales del período únicamente GANA quedó a cargo del gobierno (Ver Anuario 2006). 
Tabla 9: La composición del Ejecutivo durante la administración Berger, 2004-2008

\begin{tabular}{|c|c|c|}
\hline POSICIÓN & FUNCIONARIO EN 2007 & $\begin{array}{c}\text { FUNCIONARIOS } \\
\text { ANTERIORES* }\end{array}$ \\
\hline Presidente & Óscar Berger & $\mathrm{n} / \mathrm{a}$ \\
\hline Vicepresidente & Eduardo Stein & $\mathrm{n} / \mathrm{a}$ \\
\hline & MINISTROS & \\
\hline Ministerio de Educación & María del Carmen Aceña & - \\
\hline Ministerio de Energía y Minas & Carmen Urízar & $\begin{array}{l}\text { Roberto González y } \\
\text { Luis Romeo Ortiz }\end{array}$ \\
\hline $\begin{array}{l}\text { Ministerio de Agricultura y } \\
\text { Alimentación }\end{array}$ & Bernardo de Jesús López & Álvaro Aguilar \\
\hline Ministerio de Gobernación & Adela de Torrebiarte & $\begin{array}{l}\text { Carlos Vielmann y } \\
\text { Arturo Soto }\end{array}$ \\
\hline Ministerio de Finanzas Públicas & Mefi Eliud Rodríguez & $\begin{array}{l}\text { Hugo Beteta y } \\
\text { María Antonieta de } \\
\text { Bonilla }\end{array}$ \\
\hline Ministerio de Relaciones Exteriores & Gerth Rosenthal & Jorge Briz \\
\hline Ministerio de Cultura y Deportes & Enrique Matheu & Manuel Salazar \\
\hline $\begin{array}{l}\text { Ministerio de Trabajo y Previsión } \\
\text { Social }\end{array}$ & Rodolfo Colmenares & Jorge Gallardo \\
\hline $\begin{array}{l}\text { Ministerio de Ambiente y Recursos } \\
\text { Naturales }\end{array}$ & Mario Dary & - \\
\hline $\begin{array}{l}\text { Ministerio de Comunicaciones, } \\
\text { Infraestructura y Vivienda }\end{array}$ & Francisco Unda & Eduardo Castillo \\
\hline Ministerio de Economía & Luis Estrada & Marcio Cuevas \\
\hline $\begin{array}{l}\text { Ministerio de Salud Pública y } \\
\text { Asistencia Social }\end{array}$ & Alfredo Privado & $\begin{array}{l}\text { Marco Tulio Sosa y } \\
\text { Víctor Gutiérrez }\end{array}$ \\
\hline Ministerio de la Defensa & Ronaldo Leiva & $\begin{array}{l}\text { César Méndez y } \\
\text { Francisco Bermúdez }\end{array}$ \\
\hline
\end{tabular}

*No se señala su formación académica por cuestión de espacio.

n/a: No aplica.

Fuente: Elaboración propia, según datos del Gobierno de Guatemala, www.guatemala.gob.gt y notas de prensa. 
Finalmente, es importante hacer notar que a lo largo de los cuatro años de gobierno, solamente uno de los ministros fue indígena (Manuel Salazar) y solamente cuatro fueron mujeres. Destaca el caso de Adela de Torrebiarte, primera mujer en llegar a la cartera de Gobernación, la cual es probablemente la más compleja de todas dado el contexto actual en Guatemala. En los otros cargos del Ejecutivo hubo mayor balance, pero no en forma significativa. En términos de diversidad, en el año 2007 de un total de 37 funcionarios del Ejecutivo, 4 fueron indígenas y 11 fueron mujeres.

\section{PODER LEGISLATIVO}

\section{Conformación del Congreso}

Los partidos políticos guatemaltecos tienen ciertas características comunes: tienen débil definición ideológica, se aglutinan en torno a la figura de un líder, son poco institucionalizados, no cuentan con bases sólidas, se fragmentan en poco tiempo y desaparecen con facilidad del panorama político porque pierden legitimidad ante el electorado. ${ }^{44}$ Lo anterior impacta la composición del Congreso. La coalición GANA y los partidos UNE y FRG ejercieron un claro predominio en los primeros años de la legislatura saliente (que asumió el 14 de enero, 2004). Sin embargo, el número de partidos políticos y la correlación de fuerzas dentro del Organismo Legislativo sufrieron cambios importantes a lo largo del período. ${ }^{45}$ El transfuguismo de los diputados y el rompimiento de la alianza GANA, aunado a la fragmentación partidaria, tuvo como resultado el cambio en el número de diputados de ciertas bancadas y el aumento de las mismas, pasando de 10 bancadas al inicio de la legislatura a 17 al finalizar el período. ${ }^{46}$

La Tabla 10 muestra el alto grado de fragmentación ocurrido en el período legislativo que culminó el 14 de enero de 2008, así como los cambios ocurridos luego de la elección de 2007.

45 El fenómeno del transfuguismo afectó a la gran mayoría de las bancadas y grupos parlamentarios. Únicamente tres bancadas se mantuvieron de la misma forma en que quedaron integradas al iniciar el período legislativo en enero de 2004, siendo éstas la DCG (1 diputado), DIA (1 diputado) y la URNG (2 diputados). Una de las tendencias fue el incremento en el número de diputados independientes y otra el aumento del número de diputados de la UNE, el FRG, PP y PAN. De hecho, la UNE recuperó su número original de diputados pese a haber tenido pérdidas durante el período legislativo, y la bancada de PP se duplicó. La evidencia demuestra que la práctica del transfuguismo se encuentra arraigada en el Congreso, lo cual refleja el bajo nivel de compromiso partidario de algunos legisladores. Ello hace que la correlación de fuerzas en el hemiciclo parlamentario no sea estable ni permanente, no obedeciendo al ejercicio parlamentario de los partidos políticos, sino más bien a otro tipo de prácticas que dan como resultado rupturas en los bloques, fragmentando la configuración del mapa legislativo.

46 Mack, Luis, El Transfuguismo Parlamentario. 
Tabla 10: Diputados y afiliación política 2004-2007

\begin{tabular}{lrrr}
\hline \multicolumn{1}{c}{ Partido Político } & 2004 & 2007 & $\begin{array}{c}\text { Nuevo Congreso: } \\
\text { 2008-2011 }\end{array}$ \\
\hline PP-MR-PSN (GANA) & 47 & 27 & 37 \\
FRG & 43 & 29 & 14 \\
UNE & 32 & 27 & 51 \\
PAN & 17 & 14 & 3 \\
UNIONISTA & 7 & 5 & 7 \\
ANN & 6 & 3 & 0 \\
URNG & 2 & 2 & 2 \\
UD & 2 & 1 & 1 \\
DIA & 1 & 1 & 0 \\
DCG & 1 & 1 & 0 \\
Bien & - & 1 & 0 \\
EG & - & 2 & 4 \\
Movimiento Reformador & - & 4 & 0 \\
PP & - & 7 & 29 \\
Bancada Solidaridad & - & 13 & 0 \\
UCN & - & - & 5 \\
Independientes & - & 158 & 5 \\
CASA & 158 & & 158 \\
TOTAL & & & 5 \\
\hline
\end{tabular}

Fuente: Elaboración de autoras de acuerdo con información del Congreso de la República.

\section{Funcionamiento}

La forma interna en que se asignan los recursos y derechos parlamentarios a los diputados o partidos políticos influye en las decisiones y conducta de los mismos. Los puestos en la Junta Directiva y en las presidencias de las Comisiones de trabajo proveen a los partidos políticos y diputados que logran obtener estos puestos una importante cuota de poder. La Junta Directiva del Congreso se renueva cada principio de año, lo cual es siempre motivo de negociaciones entre los partidos. El mayor revés en 2007 lo sufrió la bancada del partido del gobierno saliente, GANA, que no obtuvo ninguna posición en la misma, hecho relevante ya que por primera vez desde el inicio de la apertura democrática un partido de gobierno no tuvo representación en la Junta Directiva de ese Organismo. Ello se debió en parte a la fuga de diversos diputados a otras bancadas, lo que disminuyó la fuerza de la bancada del partido oficial. La presidencia del Congreso fue ejercida por el PAN y las vicepresidencias por el FRG, UNE y Solidaridad. ${ }^{47}$

47 El bloque Solidaridad, se formó con diputados disidentes de diferentes partidos a lo largo de la legislatura 2004-2007. 
En lo referente a las Comisiones de Trabajo, el total de comisiones ascendió a 46 en 2007 (32 comisiones establecidas en la ley más las comisiones extraordinarias y específicas). A cada bancada le corresponde en comisiones un porcentaje equivalente al que tiene en el pleno. La distribución de las comisiones en 2007 se observa en la Tabla 11.

Tabla 11: Distribución de Comisiones de Trabajo en el Congreso en 2007

\begin{tabular}{cc}
\hline Bancada & Número de Comisiones \\
\hline UNE & 8 \\
FRG & 10 \\
PP & 7 \\
PAN & 5 \\
GANA & 4 \\
UCN & 3 \\
SOLIDARIDAD & 0 \\
PU & 2 \\
EG & 1 \\
URNG & 1 \\
DIA & 1 \\
DCG & 1 \\
MR & 0 \\
ANN & 1 \\
INDEPENDIENTE & 1 \\
BIEN & 0 \\
UD & 0 \\
INTEGRACIONISTA & 0 \\
CASA & 0 \\
\hline
\end{tabular}

Fuente: Informe de Monitoreo Electoral, PROLEY.

Según representantes de la Comisión de Asuntos Técnicos del Congreso, varias de las comisiones del Congreso no son apetecidas por los diputados, debido a la temática; ello provoca que ciertas salas de trabajo no cuenten con el número de diputados que demanda la Ley Orgánica (15 mínimo y 21 máximo) y que por tanto no emitan dictámenes ni propongan iniciativas. Por el contrario, existen comisiones que son altamente codiciadas por su naturaleza, las cuales tienden a terminar bajo el control de los partidos mayoritarios. La distribución de algunas de esas comisiones importantes en 2007 se muestra en la Tabla 12. 
Tabla 12: Partidos que presidieron las principales Comisiones de Trabajo del Congreso en 2007

\begin{tabular}{|c|c|}
\hline $\begin{array}{l}\text { Partido político que desempeñó } \\
\text { la presidencia de la Comisón }\end{array}$ & Comisión \\
\hline \multirow{4}{*}{ UNE } & Finanzas \\
\hline & Asuntos Electorales \\
\hline & Asuntos Municipales \\
\hline & Derechos Humanos \\
\hline \multirow{2}{*}{ PP } & Gobernación \\
\hline & Probidad \\
\hline Unionista & Economía \\
\hline \multirow{2}{*}{ GANA } & Reforma del Sector Financiero \\
\hline & Trabajo \\
\hline \multirow{4}{*}{ FRG } & Energía y Minas \\
\hline & Relaciones Exteriores \\
\hline & Legislación y Puntos Constitucionales \\
\hline & Comunicaciones, Transporte y Obras Publicas \\
\hline
\end{tabular}

Fuente: Elaboración DISOP/ASIES según información del Congreso de la República.

\section{Producción de leyes}

El período legislativo 2004-2008 se caracterizó por una baja productividad, la cual se explica en parte por el hecho que el Ejecutivo no contó con una bancada mayoritaria. Esta situación se agravó en el año 2007 por el inicio del proceso electoral, lo que dificultó aún más alcanzar consensos para legislar. En el período legislativo 2000-2004 se aprobaron 324 Decretos, mientras que en el período 2004-2008 sólo se aprobaron 234.

A principios de 2007 la Junta Directiva del Congreso acordó una agenda con el Ejecutivo que incluía legislación en diversos temas. A pesar que se sostuvieron varias reuniones de coordinación entre los dos organismos, al final el rendimiento fue menor al de anteriores directivas. Pasada la primera vuelta electoral, los partidos políticos UNE y PP siguieron trabajando en sus campañas, motivo por el cual la actividad en el Congreso fue escasa. En noviembre, la atención legislativa estuvo centrada en la aprobación del presupuesto de gobierno para el 2008. ${ }^{48}$ Hacia finales del período legislativo se dio la aprobación de una controversial ley de indemnización, prebendas y beneficios económicos para los diputados (Reformas a la Ley del Servicio Civil del Legislativo), lo que generó múltiples protestas de diversos sectores sociales y los medios de comunicación. Finalmente el Congreso se vio obligado a dar marcha atrás en vista de la presión social y un dictamen adverso de la Corte de Constitucionalidad. 
En síntesis, la producción de leyes fue baja en 2007. No obstante, factores como la presión internacional incidieron en que se aprobaran algunas leyes relevantes durante el año, tal como se observa en la Tabla 13, en la cual también se muestran las leyes que quedaron pendientes y que deberán ser discutidas por la nueva legislatura a partir del 14 de enero, 2008.

Tabla 13: Leyes aprobadas y leyes que quedaron pendientes durante la legislatura 2007

LEYES APROBADAS EN 2007

Comisión contra la Impunidad en Guatemala

Convenio de La Haya sobre Adopciones Internacionales

Ley de Registro de Terminales Móviles Robadas

Ley de Garantías Mobiliarias

Ley del Consejo de Atención al Migrante Guatemalteco

Ley de Adopciones

Ley del Presupuesto del Estado para 2008

Ley de Regulación del Ejercicio de la Enfermería

Ratificación del Convenio que crea la visa única centroamericana

Reformas a la Ley del Servicio Civil del Legislativo (posteriormente derogada)
LEYES PENDIENTES

Ley de armas y municiones

Ley de empresas privadas de seguridad

Ley marco del sistema nacional de seguridad

Ley de desarrollo rural

Ley de servicio civil

Reformas a la Ley Orgánica de la Contraloría

Reformas a la Ley de Contrataciones

Ley de acceso a la información

Ley marco de educación

Ley marco de salud

Fuente: Prensa Libre, 21 de diciembre, 2007.

\section{RELACIÓN ENTRE LOS PODERES DEL ESTADO Y RELACIONES ENTRE NIVELES DE GOBIERNO}

La labor de fiscalización del Congreso sobre el Ejecutivo se dificultó por la relación tirante entre el presidente y el Organismo Legislativo. El año 2007 inició con la ausencia del presidente Berger en la plenaria en el Congreso de la República para la presentación del Informe del Año 2006. En el año 2007 hubo únicamente dos interpelaciones: una a la ministra de Educación en septiembre, la cual pasó casi desapercibida, y una al ministro de Gobernación Carlos Vielmann en marzo -como resultado de la crisis derivada del asesinato de tres diputados salvadoreños en territorio guatemalteco-la que culminó con la renuncia del mismo luego que recibiera un voto de falta de confianza de 87 legisladores.

Otra relación conflictiva que amerita ser mencionada es la del presidente del Ejecutivo con el Alcalde de la Ciudad de Guatemala, el ex presidente Álvaro Arzú. Ambos fueron 
miembros del partido PAN pero por cuestiones de liderazgo se desligaron de ese partido; Arzú fundó un nuevo partido (Partido Unionista) en el 2000 y Berger fue electo presidente con la coalición GANA a finales de 2003. A pesar de tener una trayectoria y perspectivas ideológicas similares, han existido rencillas entre ambos funcionarios que han afectado el desarrollo de proyectos comunes a lo largo de la administración saliente.

\section{EVALUACIÓN GENERAL SOBRE EL FUNCIONAMIENTO Y CALIDAD DE LA DEMOCRACIA}

Puede concluirse que el año 2007 fue un año de contrastes para la democracia guatemalteca. La democracia es ciertamente más que elecciones libres, pero en este año el proceso político giró en torno a ellas. En el lado positivo, las elecciones fueron exitosas desde el punto de vista técnico, no quedando duda -con excepción de dos municipios en los que hubo que repetir la elección- en cuanto a la validez de las mismas. Los actores políticos mostraron signos de madurez política al reconocer prontamente los resultados, lo que coadyuvó a generar un ambiente de estabilidad poselectoral. También fue visto como positivo el que se diera la descentralización de las mesas receptoras de votos, lo que influyó en una mayor participación del electorado, en especial en zonas aisladas del país. Otro aspecto que puede considerarse positivo para el sistema democrático es que la decisión final en cuanto a quién ejercerá la presidencia del país en los próximos años estuvo en las manos de los electores del área rural y el área urbana interior del país, habiendo perdido la hegemonía que mantenían los capitalinos en dicha decisión.

La elección arrojó resultados novedosos, ya que es la primera vez que un candidato de centro-izquierda (social-demócrata) llega a ejercer la presidencia, aunque no queda claro cuánto margen de maniobra tendrá para implementar políticas asociadas con esa tendencia y si en general el equipo de gobierno y los cuadros del partido comparten dicha tendencia política. También puede verse como un aspecto positivo y sin precedente el que el proceso de traspaso de mando de una administración a otra se haya realizado de forma técnica.

Más allá de las elecciones, la aprobación de la CICIG como un mecanismo que apoyará la investigación acerca del crimen organizado en Guatemala es un hecho trascendente. La complejidad del problema hace necesario que actores externos, con respaldo político internacional, examinen a fondo las redes de penetración de los llamados grupos paralelos en las estructuras de seguridad del Estado.

No obstante lo anterior, en el año se dieron hechos que empañaron el proceso electoral. El asesinato de miembros de diversos partidos políticos participantes, incluyendo personas cercanas a los principales candidatos, mostró que la violencia política no ha desaparecido, pese a que en elecciones anteriores había disminuido significativamente. Mucha de esta violencia fue atribuida a la acción de las mafias que han penetrado las estructuras de seguridad del Estado y que han intentado penetrar también las estructuras de los partidos políticos. Dicha penetración va más allá del proceso electoral y ha llegado a afectar la vigencia del Estado de Derecho. El asesinato de tres diputados salvadoreños en marzo evidenció el grado de impunidad que todavía prevalece en el país. Por otro lado, la inseguridad 
continuó afectando a los guatemaltecos sin que las instituciones a cargo de la seguridad pública pudieran ejercer control sobre la delincuencia o las mafias organizadas. Ello llevó a que se retomara un discurso de corte autoritario por parte de algunos candidatos como propuesta para combatir el fenómeno.

En otro aspecto, también fue negativo que el proceso electoral se caracterizara una vez más por la fragmentación en el sistema de partidos políticos en el país. Tanto la izquierda como la derecha mostraron incapacidad para llegar a acuerdos que les permitieran presentar un frente común y tener así mayores posibilidades de tener un impacto en las elecciones. Este divisionismo fue particularmente negativo para la izquierda guatemalteca, la cual obtuvo magros resultados electorales, a pesar de la novedosa candidatura de la primera mujer indígena en postularse a ese cargo en el país, Rigoberta Menchú.

En síntesis, la democracia dio un paso adelante en Guatemala en el año 2007 al solventarse exitosamente el sexto proceso electoral. El gobierno quedó en manos de un gobernante civil, como ha sido el caso desde la apertura democrática de 1985. No obstante, también se hizo evidente que el nuevo mandatario enfrentará una serie de dificultades y complejos desafíos, en particular combatir la penetración del crimen organizado en las instituciones del Estado, brindar seguridad a los ciudadanos, mejorar la calidad de vida de los guatemaltecos -incluyendo reducir mediante políticas públicas eficaces los altos niveles de pobreza existentes. Los logros o fracasos que se obtengan en estos temas incidirán indudablemente en el rumbo que tome la democracia guatemalteca en el futuro cercano.

\section{REFERENCIAS}

Asociación de Investigación y Estudios Sociales (ASIES). 2007. Cápsula Informativa. Guatemala: ASIES.

Asociación de Investigación y Estudios Sociales (ASIES). 2007. Evaluación Económica: Primer Semestre 2007. Guatemala: ASIES.

Asociación de Investigación y Estudios Sociales (ASIES). 2004. Monografía de Partidos Políticos 2000-2004. Guatemala: ASIES.

Azpuru, Dinorah. 2007. Cultura política de la democracia en Guatemala: 2006. Guatemala: FLACSO, USAID, Vanderbilt University.

Banco de Guatemala. 2007. Desempeño Macroeconómico reciente y estimación de cierre 2007. Guatemala: Banco de Guatemala.

BBC News, "Guatemala campaign deaths mount". 14 de agosto, 2007. Reino Unido.

BBC News, "EU Alarm at Guatemala Violence". 24 de agosto, 2007. Reino Unido.

Congreso de la República de Guatemala. [En línea] <www.congreso.gob.gt> [Varias consultas septiembre, octubre y noviembre, 2007].

El Paso Times, "Guatemala sube recaudación fiscal casi 16\%", 7 de enero, 2008. www.elpasotimes.com

El Periódico, "Hay aspectos positivos", entrevista a Diego García Sayán, Jefe de la Misión de Observación de las Elecciones de la Organización de Estados Americanos. 3 de noviembre, 2007. Guatemala.

El Periódico, "CEPAL: Guatemala creció un 5.6 por ciento este año". 14 de diciembre, 2007. Guatemala.

Gobierno de Guatemala. [En línea] <www.guatemala.gob.gt> [Varias consultas septiembre y octubre 2007].

Inforpress, Cambios ministeriales: ¿Hacia la inmovilidad? 23 de febrero, 2007. Guatemala.

Instituto Nacional de Estadística, 2006. Cómo estamos viviendo, Encuesta Nacional sobre Condiciones de Vida. Guatemala: Instituto Nacional de Estadística.

La Prensa, "El proceso electoral más observado", 8 de septiembre, 2007. Honduras. 
Lacey, Marc. "Choosing a Future From Tainted Pasts", New York Times, 11 de septiembre, 2007. Nueva York.

Mack, Luis. 2005. El Transfuguismo Parlamentario. Guatemala: FLACSO.

Miami Herald, "Guatemala's Candidates Run the Gamut", 30 de agosto, 2007. Miami.

Prensa Libre, "Un doloroso penúltimo lugar", Editorial, 29 de noviembre, 2007. Guatemala.

Prensa Libre, "Istmo acuerda unión", 21 de diciembre, 2007. Guatemala.

Prensa Libre, "Con Poder", 21 de diciembre, 2007. Guatemala.

Prensa Libre, "Aumenta Salario Mínimo", 29 de diciembre, 2007. Guatemala.

Prensa Libre, "EEUU deportó a 392 guatemaltecos en primera semana de 2008", 9 de enero, 2008.

Guatemala.

PROLEY. 2007. Informe de Monitoreo Electoral. Guatemala.

Programa Nacional de Competitividad, PRONACOM. [En línea] <www.pronacom.org > [Consulta 11-11-2007].

Programa de Naciones Unidas para el Desarrollo, 2007. Informe estadístico de la violencia en Guatemala. Programa de Seguridad Ciudadana y Prevención de la Violencia. Diciembre, 2007.

Roig-Franzia, Manuel. "Choosing a Future From Tainted Pasts". 4 de noviembre. 2007. Washington Post $4^{\mathrm{a}}$ (en línea).

Solano, Gustavo. 2007. Conferencia "Sistema de Seguridad". Guatemala: Centro ESTNA.

Tribunal Supremo Electoral. [En línea] <www.tse.org.gt> [Varias consultas septiembre, octubre, noviembre y diciembre, 2007].

Tribunal Supremo Electoral. 2004. Memoria de las Elecciones Generales 2003. Guatemala: Tribunal Supremo Electoral.

United Nations Development Program, 2006. Beyond scarcity: Power, poverty and the global water crisis. Human Development Report 2006. Nueva York: UNDP.

Univision.com, despacho de Agencia EFE, "UE dice que elecciones de Guatemala fueron un ejemplo magnífico para el mundo". 6 de noviembre, 2007.

Dinorah Azpuru es Doctora (Ph.D.) en Ciencia Política de la Universidad de Pittsburgh. Actualmente es profesora de Ciencia Política y Relaciones Internacionales en Wichita State University, Estados Unidos. Es también Asociada del centro de investigación ASIES en Guatemala. Sus áreas de especialización son política comparada, relaciones internacionales y opinión pública.

(E-mail: dinorah.azpuru@wichita.edu)

Ligia Blanco tiene una Maestría en Ciencia Política de la Universidad de Pantheon-Assas Paris II. Actualmente es consultora en ASIES y profesora de Ciencia Política en la Universidad Rafael Landívar, ambos en Guatemala. Sus áreas de especialización son parlamento, partidos políticos y procesos electorales.

(E-mail: lblanco@asies.org.gt) 